\title{
Bayesian network to optimize the first dose of antibiotics: application to amikacin
}

\begin{abstract}
Objective: To construct and validate a network to predict the first dose of amikacin. Methods: Anthropometric and therapeutic data were recorded for 120 patients. Bayesian network (BN) was built to predict the dose to achieve a fixed target peak concentration of $64 \mathrm{mg} / \mathrm{l}$. In 40 subjects, doses predicted with the BN (BND) and based on body weight (BWD) were compared with adjusted doses calculated using a pharmacokinetic software (MM-USCPACK; BID). Results: The calculated dose differed by $<20 \%$ from the ideal dose in $62.5 \%$ of the patients with the BN and in $43.8 \%$ of the patients with the BW. Conclusion: BN is a promising approach to optimize the prediction of the first dose.
\end{abstract}

First draft submitted: 18 November 2015; Accepted for publication: 17 February 2016; Published online: 4 April 2016

Keywords: amikacin $\bullet$ aminoglycosides $\bullet$ Bayesian network $\bullet$ forecasting $\bullet$ machine learning - model • nonparametric • pharmacokinetics • statistic

In serious clinical situations, such as myocardial infarction or septic shock, it is necessary to quickly achieve effective drug concentration [1-7]. For some drugs, interindividual variability is important: a single dose, administered to different patients does not lead to the same concentration or the same effects [8-10]. Individualization of drug dosage can often be done after measuring drug concentration during the therapy, but this is not possible for the first administration. For some drugs, calculation rules can be used to estimate the most appropriate dose for each patient, based on clinical descriptors such as weight or body surface area. The French National Security Agency of Medicines and Health Products has proposed using an international recommendation on a dosage calculation based on the patient's body weight [11]. Beyond the simplicity of such methods, their relevance is questionable: can the variability of the response properly describe from a single information?

The individual ideal first dose of amikacine may also be considered as the result of a more complete knowledge about the patients. Such knowledge may be the result of the complex interaction of numerous clinical descriptors (age, sex, weight, renal function). Powerful tools are commonly used in others disciplines (engineering, economy, meteorology, etc. [12-14]) to handle similar problems. Among them, Bayesian networks (BN) seem to be well suited to this kind of problems, and have already been used several times in medical environment $[15,16]$.

The objective of this study was to construct and evaluate the capacity of a BN to predict the first dose of amikacin in adult patients.

\section{Patients \& methods}

A database of adult patients suffering from sepsis and treated with amikacin was used. This multicenter database (seven French centers participated in data collection) has been described in previous publications from our group [17,18]. For each patient, anthropometric data (age, sex, weight, height,
Guillaume Debeurme', Michel Ducher ${ }^{*}, 1$, Elodie Jean-bart ${ }^{1}$, Sylvain Goutelle ${ }^{1,2,3}$ \& Laurent Bourguignon $^{1,2,3}$

${ }^{1}$ Hospices Civils de Lyon, Groupement Hospitalier de Gériatrie, Hôpital Antoine Charial, Service Pharmaceutique, 40 avenue de la Table de Pierre, 69340 Francheville, France

2Laboratoire de Biométrie et Biologie Evolutive, CNRS UMR 5558, Université de Lyon, 69622 Villeurbanne, France 3Université Lyon 1, ISPB - Faculté de Pharmacie de Lyon, 8 avenue Rockefeller, 69373 Lyon cedex 08, France

*Author for correspondence:

Tel.: +33472 323487

Fax: +33472323438

michel.ducher@chu-lyon.fr 
serum creatinine) and therapeutic data (amikacin dose administered, route of administration, times and dates of each dose, duration of infusion) were available. Weight and creatinine changes during treatment were also recorded. From these data, creatinine clearance was estimated by using the Jelliffe and Jelliffe formula for unstable creatinine [19,20], and the BMI was calculated. According to the French National Security Agency of Medicines and Health Products [11] and Wurtz et al. [21], patient's weight was examined as total weight, ideal weight and dosing weight to avoid overdose in obese population.

One hundred and twenty subjects were randomly extracted from this database, and divided into two groups, one for the building of the $\mathrm{BN}$ (80 subjects, learning subgroup), the other (40 subjects, validation subgroup) for external validation of the model.

In a first step of the analysis using a pharmacokinetic software (MM-USCPACK, version 15.2, University of Southern California, CA, USA), the individual pharmacokinetic parameters of every patient were estimated with a Bayesian approach and a two-compartment model. Using this information, the exact dose to achieve a defined target peak concentration was calculated for each patient (ideal dose). This target peak concentration was set at $64 \mathrm{mg} / \mathrm{l}$, as proposed by the most recent French guidelines [11].

In the second step of the analysis, we used the BN. We used Netica (Norsys Software Corp., Vancouver, Canada) to develop the model. $\mathrm{BN}$ is a directed graph, it consists of nodes and directed edges (arrows). Each edge points from one node (called the parent) to another node (known as the child). In a $\mathrm{BN}$ each node is used to represent a random variable, and each directed arrow represents dependence between variables. The probabilistic dependencies between variables are calculated using the conditional probability as defined by Bayes' theorem [22].

To build BN we should build a structure (graph model) and estimate parameters (conditional probabilities table) of the model. This step is so called learning step. The computation of probabilities is always possible. Then, the BN does not need any assumption. All the variables (nodes) are included in the model. Only the dependence between variable (arrow) was selected to build the structure of the network. The modeling procedure consisted to find the best structure of a BN. The idea is to browse all possible configurations of the arcs between nodes. The network structure was optimized using the algorithm of Tabu [23], a local search procedure. EM algorithm was used to estimate parameters of the model. Briefly, EM learning repeatedly takes a Bayes net and uses it to find a better one by doing an expectation (E) step followed by a maximiza- tion (M) step. In the E step, it uses regular Bayes net inference with the existing Bayes net to compute the expected value of all the data, and then the $M$ step finds the maximum likelihood Bayes net given the new dataset. At each stage the EM algorithm guarantees that the maximum likelihood must increase. The procedure is ended when the maximum is reached and all probabilities estimated.

In a third step of the analysis, the predictive performance of the BN was evaluated with the validation subgroup. Using patient's information, the network was used to predict the dose to achieve the target concentration.

\section{Statistical analysis}

All the variables are discretized in amplitude interval to define statistical event. Ranges are defined as a combination of equal distribution of values between every group. The discretization of continuous variables is the result of a balance with the limitation of combinatory to preserve, the frequency of observation of the statistical event (to limit the fluctuation of the probabilities) and clinical interest of the prediction.

$\mathrm{BN}$ predicted doses were provided as a dose range. The median of the range was used for the statistical analysis.

The predicted doses calculated using the network were compared with the ideal doses determined retrospectively by the pharmacokinetic software. The same comparison was made for bodyweight-based doses, using a fixed dose of $30 \mathrm{mg} / \mathrm{kg}$. Differences between learning and validation subgroups were assessed using a paired Student's $t$-test.

Performances of the two methods of dose calculation were compared through the calculation of bias (mean prediction error) and precision (mean squared error of prediction) [24]. This quadratic mode of expression of the precision is used to penalize the large prediction errors. A low value of this criterion reflects a good accuracy of the predictions. To compare methods, a mountain plot (or 'folded empirical cumulative distribution plot') was created by computing a percentile for each ranked difference between a method and the reference method. To get a folded plot, the following transformation was performed for all percentiles above 50: percentile $=100$ - percentile. These percentiles are then plotted against the differences between the two methods [25].

Goodness of fit of the network was assessed by the computation of the area under the receiver operating characteristic curve. Spherical payoff was used to quantify the quality of the forecasting. The percentage of patient for whom calculated dose differs by $<20 \%$ of the ideal dose (estimated by the pharmacokinetic approach) was calculated for both methods. 


\section{Results}

Table 1 shows variables and their values used in the $\mathrm{BN}$. The main characteristics of the population are presented in Table 2. From 120 cases originally selected for the study, 12 were excluded because of missing data preventing the estimation of the pharmacokinetic parameters. The mean ideal dose to achieve the target concentration was estimated at $1299.2 \mathrm{mg}(23.3$ $\mathrm{mg} / \mathrm{kg})$ and standard deviation at $264 \mathrm{mg}(5.7 \mathrm{mg} / \mathrm{kg})$ by the pharmacokinetic software (MM-USCPACK, version 15.2, University of Southern California). In Table 3, there is no significant difference between variables in learning subgroup $(\mathrm{n}=76)$ and validation subgroup $(\mathrm{n}=32)$.
The $\mathrm{BN}$ had nine knots. Its structure is shown in Figure 1. Variables explaining the dose found by the Tabu algorithm were: sex, weight and ideal weight, excess body weight, BMI, height, age and creatinine clearance. Area under the receiver operating characteristic curve of the BN (Figure 2) was equal to $0.89(95 \%$ CI; $\mathrm{p}=4 \times 10-14)$.

During the validation step, the mean dose necessary to achieve a peak of $64 \mathrm{mg} / \mathrm{l}$ of amikacin calculated by the network for the 32 patients was 1261 mg (standard deviation [SD]: $114 \mathrm{mg}$ ). For the same patients, the mean dose calculated using body weight was $1650 \mathrm{mg}$ (SD: $395 \mathrm{mg}$ ). The mean ideal dose determined retrospectively by the pharmacokinetic

\section{Table 1. Data discretization.}

\begin{tabular}{|c|c|c|c|c|}
\hline \multirow[t]{2}{*}{ Variable } & \multicolumn{4}{|c|}{ Values } \\
\hline & 1 & 2 & 3 & 4 \\
\hline Age (year) & $0-74$ & $75-79$ & $80-84$ & $\geq 85$ \\
\hline Total weight $(\mathrm{kg})$ & $0-49$ & $50-59$ & $60-69$ & $\geq 70$ \\
\hline Ideal weight $(\mathrm{kg})$ & $0-49$ & $50-59$ & $60-69$ & $\geq 70$ \\
\hline Excess body weight $(\mathrm{kg})$ & $\leq 0$ & $1-10$ & $>10$ & \\
\hline BMI $\left(\mathrm{kg} / \mathrm{m}^{2}\right)$ & $0-18.4$ & $18.5-24$ & $25-29$ & $\geq 30$ \\
\hline Height $(\mathrm{cm})$ & $0-159$ & $160-164$ & $\geq 165$ & \\
\hline Creatinine clearance ( $\mathrm{ml} / \mathrm{min})$ & $15-29$ & $30-59$ & $\geq 60$ & \\
\hline
\end{tabular}

\section{Table 2 Baseline characteristics of patients $(n=108)$.}

\begin{tabular}{|c|c|}
\hline Characteristics & Mean \pm SD (range) \\
\hline Age (year) & $79.2 \pm 7.6(48-92)$ \\
\hline Total weight (kg) & $57.6 \pm 12.6(33-90)$ \\
\hline Ideal weight* $(\mathrm{kg})$ & $56.2 \pm 5.8(42.5-74.8)$ \\
\hline Excess body weight ${ }^{\ddagger}(\mathrm{kg})$ & $1.3 \pm 11.5(-21.3-33.1)$ \\
\hline Dosing weight ${ }^{\S}(\mathrm{kg})$ & $56.8 \pm 7.4(42.7-77.8)$ \\
\hline BMI" $\left(\mathrm{kg} / \mathrm{m}^{2}\right)$ & $22.4 \pm 4.4(13.3-35.6)$ \\
\hline Height $(\mathrm{cm})$ & $160.3 \pm 8.3(138-183)$ \\
\hline Creatinine clearance (ml/min) & $45.1 \pm 14.7(13.6-84.2)$ \\
\hline Dose to achieve $64 \mathrm{mg} / \mathrm{l}$ of amikacin (mg) & $1299.2 \pm 264(500-1800)$ \\
\hline Dose to achieve $64 \mathrm{mg} / \mathrm{l}$ of amikacin $(\mathrm{mg} / \mathrm{kg})$ & $23.6 \pm 5.7(13.3-45.5)$ \\
\hline Male/Female ratio & $30 / 78$ \\
\hline \multicolumn{2}{|c|}{$\begin{array}{l}\text { SD: Standard deviation. } \\
\text { "Lorentz's formula (ideal weight expressed in } \mathrm{kg} \text { ): Women = Height }(\mathrm{cm})-10 \\
\text { 150]/4 } \\
\text { Conditions of use: age older than } 18 \text { years; size between } 140 \text { and } 220 \mathrm{~cm} \text {. } \\
\text { "Excess body weight }=\text { Total weight }- \text { Ideal weight } \\
\text { "Dosing weight }=\text { Ideal weight }+0.43 \times \text { Excess body weight } \\
\text { "BMI = Weight }(\mathrm{kg}) /[\text { Height }(\mathrm{m})]^{2}\end{array}$} \\
\hline
\end{tabular}


Table 3. Paired Student's $t$-test for variables used in Bayesian network between the learning subgroup ( 76 subjects for the building of Bayesian network) and validation subgoup ( 32 subjects for the validation of Bayesian network) for external validation of the two populations.

\begin{tabular}{|llll|}
\hline Variable & Learning subgroup & Validation subgroup & p-value \\
\hline Size $(\mathrm{cm})$ & 160.05 & 160.81 & 0.67 \\
\hline Weight $(\mathrm{kg})$ & 58.70 & 55.00 & 0.17 \\
\hline Sex ratio (Male/Female) & $21 / 55$ & $9 / 23$ & 0.96 \\
\hline $\begin{array}{l}\text { Age (year) } \\
\text { Creatinine clearance }\end{array}$ & 79.40 & 79.00 & 0.80 \\
(ml/min) & 44.68 & 46.21 & 0.62 \\
\hline Ideal weight $(\mathrm{cm})$ & 56.06 & 56.70 & 0.62 \\
\hline $\begin{array}{l}\text { Excess body weight }(\mathrm{kg}) \\
\text { BMI }\left(\mathrm{kg} / \mathrm{m}^{2}\right)\end{array}$ & 2.64 & -1.72 & 0.10 \\
\hline $\begin{array}{l}\text { Dose to obtain } 64 \mathrm{mg} / \mathrm{l} \\
\text { by MM-USCPACK }(\mathrm{mg})\end{array}$ & 1268.42 & 21.25 & 0.11 \\
\hline
\end{tabular}

approach was $1372 \mathrm{mg}$ (SD: $263 \mathrm{mg}$ ). Paired Student's $t$-test between Bayesian predicted model and weight-based dosing method showed no significant difference between average doses. Comparison between the $\mathrm{BN}$ doses and dose calculated using body weight doses versus ideals doses (MM-USCPACK) is given in Figure 3. The bias between the predicted doses (BN and body weight method) and the ideal doses was $-111 \mathrm{mg} \pm 240 \mathrm{mg}(-5 \%)$ for the $\mathrm{BN}$ and $277 \mathrm{mg} \pm 322 \mathrm{mg}(21.7 \%)$ for the weight-based dosing ( $\mathrm{p}<0.001)$. Precision was $68,484 \mathrm{mg}^{2}$ for the $\mathrm{BN}$, versus $177,330 \mathrm{mg}^{2}$ for the calculation based on body weight $(\mathrm{p}<0.05)$.

The percentage of patients for whom the calculated dose differs by $<20 \%$ from the required dose to achieve the target dose was $62.5 \%$ for the $\mathrm{BN}$ and $43.8 \%$ for the calculation based on the weight. These results are reported in Table 4. Spherical payoff was 0.96 for our data.

Figure 3 shows the repartition of the errors with the reference methods. They are normally distributed. BN estimation shows a lower difference and lower bias than body weight (BW) determination of the dose.

\section{Discussion}

These results showed that a BN allows calculating the first dose of amikacin with more accuracy and less bias than with the actual method of calculation based on

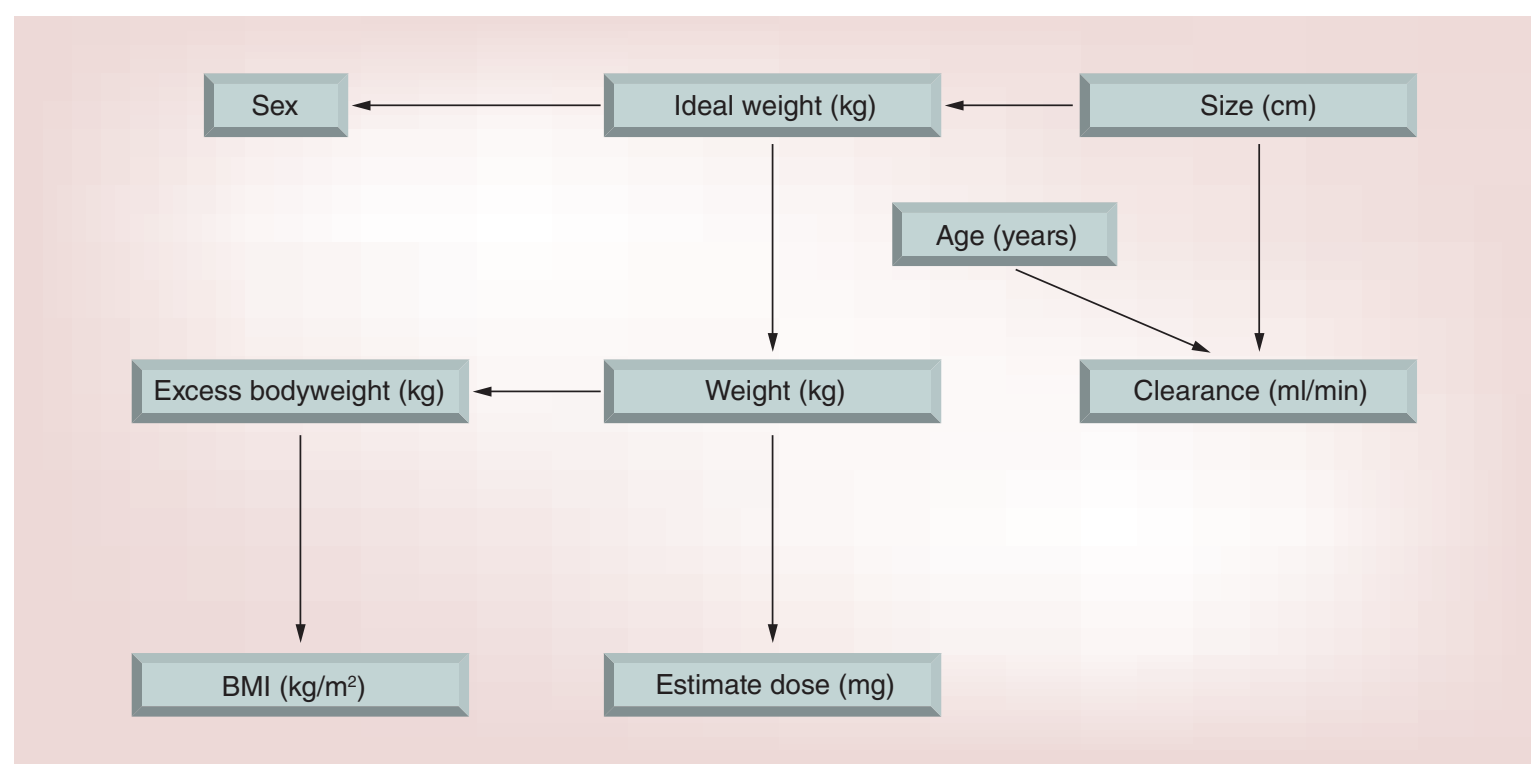

Figure 1. Bayesian network modeling the relationships to predict the first amikacin's dose (estimated dose) to achieve a fixed target peak concentration of $64 \mathrm{mg} / \mathrm{l}$. 
body weight (Figure 3). For patients of the validation cohort, the calculated dose differs by $<20 \%$ from the theoretic ideal dose for $62.5 \%$ of patients with the Bayesian method, compared with $43.8 \%$ of patients with the calculation based on weight.

The probabilistic graphical models firstly described by Judea Pearl in the 1980s ([26]) have proven to be useful tools for uncertain knowledge representation, to achieve a reasoning with missing information. They are moreover well suited for modeling complex systems [27]. The Bayesian network does not need any assumption on the nature of distribution, on covariance or continuous relationships between variables as regression methods. The computation of probabilities is always possible. The $\mathrm{BN}$ is an heuristic nonparametric approach. It is not influenced by colinearity and is robust to missing value. For these characteristics, BN are well suited for clinical data. Their applications are now common in various areas: gene regulatory networks [28], failure analysis in complex industrial systems [16], medicine [29] and epidemiology [30]. From our point of view, this paper presents the first application of this technique for the prediction of drug doses in the therapeutic field.

This tool has the advantage to display a graphical representation of knowledge easily understandable by the users, through the representation of conditional dependencies between variables (Figure 1). The basis of BN modeling is the calculation of probabilities. This calculation requires definition of the statistical events. For continuous variables, the definition of amplitude internal is required. As a consequence, intervals of weight (total and ideal, excess body weight), BMI, height, age and creatinine clearance have been defined. The dose calculated with the network was also expressed as an interval. A fixed range of $100 \mathrm{mg}$ was chosen, representing a compromise between a fine enough resolution to have clinical relevance, without reducing too much the number of patients in each category.

Many methods are used to calculate the most appropriated dosage regimen for a specific patient treated with aminoglycosides using anthropometric information and serum concentrations [31]. All these methods use observed serum concentrations to individualize the future therapy, but are not suited for the calculation of the first dose. Some authors proposed formulas to estimate patient pharmacokinetic parameters using clinical descriptors only [31-33]. These formulas are based on simple relationships between clinical parameters and descriptors (often linear relationships, between body weight and volume of distribution, for example), and are unable to take into account missing values. In contrast, $\mathrm{BN}$ use an a priori knowledge (tables of probabilities). The forecast abilities are not affected by missing data.

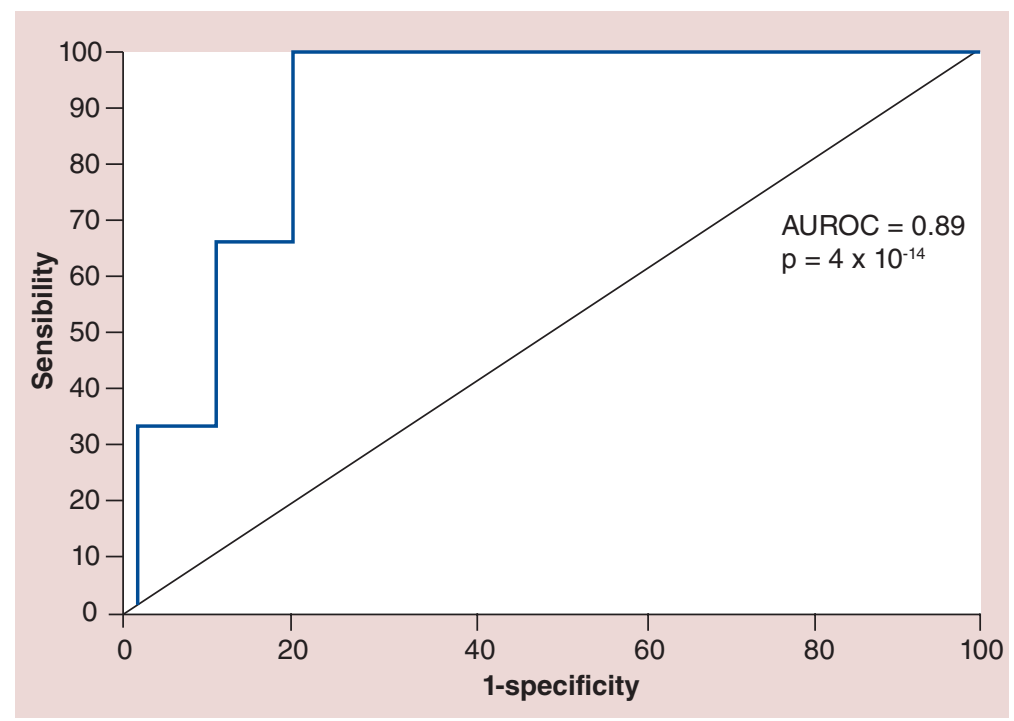

Figure 2. Receiver operating characteristic curve of Bayesian network prediction in learning subgroup $(n=76)$. Sensitivity and 1 minus specificity of first amikacin's estimated dose by the BN are shown. AUROC is 0.89 . The reported $p$-value was calculated $\left(p=4 \times 10^{-14}\right)$ to test the null hypothesis if $A \cup C=0.5$.

AUROC: Area under the ROC curve; BN: Bayesian network; ROC: Receiver operating characteristic.

This study has some limitations that should be discussed. First, we used a cohort of patients with sepsis without severity factor, which may not be representative of all the clinical situations in which an aminoglycoside can be necessary. The infection severity may influence the pharmacokinetic of aminoglycosides, as observed in patients with septic shocks [34,35]. However, in this situation, a large variability of the volume of distribution has been described [36,37], so the existence of a stable relationship between this parameter and body weight, and the relevance of a dosage calculation based on this descriptor are uncertain. Similarly, as information on possible fluid overload or dehydration was not available in the dataset used for this study, it was not possible to include this information in the $\mathrm{BN}$, although it could affect the volume of distribution of amikacine.

Second, we used a Bayesian algorithm and a pharmacokinetic approach to estimate, retrospectively, for each patient, the exact dosage regimen needed to precisely reach the efficacy target. Whereas pharmacokinetic approach is considered one of the most effective [38], it has a certain margin of error.

Third, we did not compare the performance of the BN with all the possible calculation methods for amikacin dosing, such as those using ideal weight, or dosing weight. However, in non-obese patients, the actual body weight is the only descriptor recommended for prior dosage adjustment.

Finally, overdosing and underdosing does not have the same clinical consequences. The method of cal- 


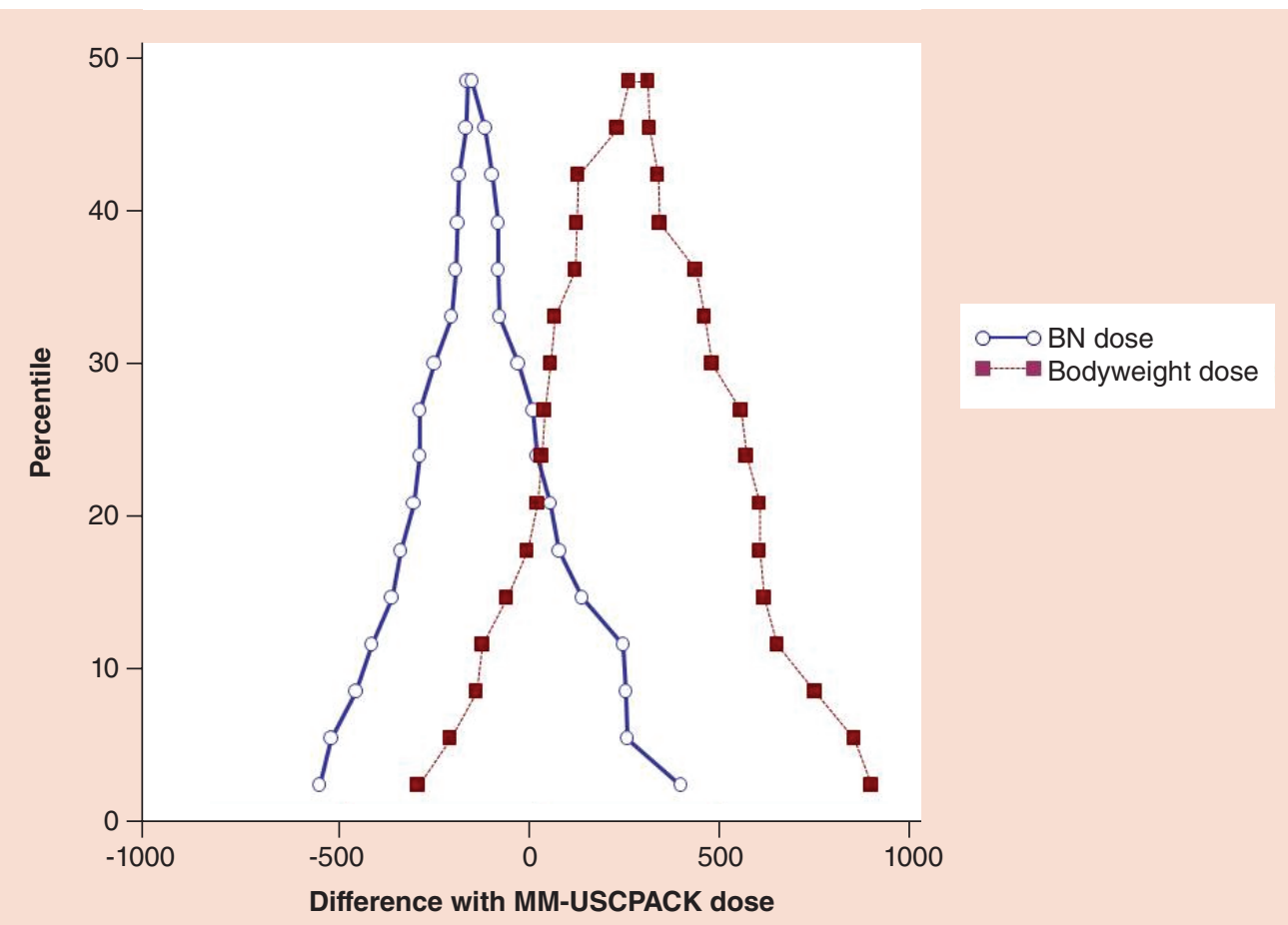

Figure 3. Mountain plot is created by computing a percentile for each ranked difference dose between Bayesian network dose and bodyweight dose methods and the reference method (USCPACK dose).

culation based on the weight of the patients has a positive bias, which corresponds to a risk of overdose. Whereas it does not affect the effectiveness of treatment, such excessive doses unnecessarily overexposed patients to a potentially toxic drug [39]. In addition, a large number of patients of this cohort were exposed to a dose significantly different from that required when using the calculation based on body weight: the use of a BN seems to significantly reduce this risk.

\section{Conclusion}

$\mathrm{BN}$ appears to be a promising approach to optimize the prediction of the first dose of amikacin. These preliminary results in an adult population should be confirmed in more specific populations, such as pediatric or elderly patients. More generally, in clinical practice, tolerance to missing data is an important advantage of this Bayesian approach. Finally, beyond the interest of this method for aminoglycosides, this study demonstrates the potential utility of such an approach for the calculation of doses of antibiotics for which blood levels are not measured in clinical practice.

\section{Table 4. Validation step between the Bayesian network and the weight-based dosing method $(30 \mathrm{mg} / \mathrm{kg})$ for 32} patients (validation subgroup).

\begin{tabular}{|c|c|c|c|}
\hline & MM-USCPACK method & Bayesian prediction model & Weight-based dosing \\
\hline Standard deviation (mg) & 263 & 114 & 198 \\
\hline \multicolumn{2}{|l|}{ Precision $\left(\mathrm{mg}^{2}\right)$} & 68484 & 177330 \\
\hline \multicolumn{2}{|c|}{$\begin{array}{l}\text { Percentage of patients whose calculated dose differs from }<20 \% \text { with } \\
\text { MM-USCPACK }(\%)\end{array}$} & 62.5 & 43.8 \\
\hline \multicolumn{2}{|c|}{$\begin{array}{l}\text { Percentage of patients whose calculated dose differs from }<10 \% \text { with } \\
\text { MM-USCPACK }(\%)\end{array}$} & 37.5 & 31.3 \\
\hline
\end{tabular}




\section{Objective}

- This work aimed to construct and validate a Bayesian network (BN) to predict the first dose of amikacin.

Results

- The mean difference between the predicted doses and the ideal doses was $-111 \mathrm{mg}$ for the BN dose and 277 mg for the BW dose.

- The calculated dose differed by $<20 \%$ from the ideal dose in $62.5 \%$ of patients with the BN, compared with the same difference obtained in $43.8 \%$ of patients with the calculation based on weight.

\section{Conclusion}

- BN appears to be a promising approach to optimize the prediction of the first dose.

Financial \& competing interests disclosure

The authors have no relevant affiliations or financial involvement with any organization or entity with a financial interest in or financial conflict with the subject matter or materials discussed in the manuscript. This includes employment, consultancies, honoraria, stock ownership or options, expert testimony, grants or patents received or pending, or royalties.

No writing assistance was utilized in the production of this manuscript.

\section{Ethical conduct of research}

The authors state that they have obtained appropriate institutional review board approval or have followed the principles outlined in the Declaration of Helsinki for all human or animal experimental investigations. In addition, for investigations involving human subjects, informed consent has been obtained from the participants involved.

\section{References}

1 Herlitz J, Wireklintsundström B, Bång A, Berglund A, Svensson L, Blomstrand C. Early identification and delay to treatment in myocardial infarction and stroke: differences and similarities. Scand. J. Trauma Resusc. Emerg. Med. 18, 48 (2010).

2 Heestermans T, Suryapranata H, ten Berg JM et al. Facilitated reperfusion with prehospital glycoprotein IIb/ IIIa inhibition: predictors of complete ST-segment resolution before primary percutaneous coronary intervention in the On-TIME 2 trial: correlates of reperfusion before primary PCI. J. Electrocardiol. 44(1), 42-48 (2011).

3 Funk DJ, Kumar A. Antimicrobial therapy for life-threatening infections: speed is life. Crit. Care Clin. 27(1), 53-76 (2011).

4 Ibrahim EH, Sherman G, Ward S, Fraser VJ, Kollef MH. The influence of inadequate antimicrobial treatment of bloodstream infections on patient outcomes in the ICU setting. Chest 118(1), 146-155 (2000).

5 Johnson MT, Reichley R, Hoppe-Bauer J, Dunne WM, Micek S, Kollef M. Impact of previous antibiotic therapy on outcome of Gram-negative severe sepsis. Crit. Care Med. 39(8), 1859-1865 (2011).

6 Shorr AF, Micek ST, Welch EC, Doherty JA, Reichley RM, Kollef MH. Inappropriate antibiotic therapy in Gramnegative sepsis increases hospital length of stay. Crit. Care Med. 39(1), 46-51 (2011).
7 Micek ST, Lloyd AE, Ritchie DJ, Reichley RM, Fraser VJ, Kollef MH. Pseudomonas aeruginosa bloodstream infection: importance of appropriate initial antimicrobial treatment. Antimicrob. Agents Chemother. 49(4), 1306-1311 (2005).

8 Pérez-Urizar J, Granados-Soto V, Flores-Murrieta FJ, Castañeda-Hernández G. Pharmacokineticpharmacodynamic modeling: why? Arch. Med. Res. 31(6), 539-545 (2000).

9 Gieschke R, Steimer JL. Pharmacometrics: modelling and simulation tools to improve decision making in clinical drug development. Eur. J. Drug Metab. Pharmacokinet. 25(1), 49-58 (2000).

10 Levy G. Predicting effective drug concentrations for individual patients. Determinants of pharmacodynamic variability. Clin. Pharmacokinet. 34(4), 323-333 (1998).

11 SPILF. AFSSAPS. GPIP. Mise au point sur le bon usage des aminosides administrés par voie injectable: gentamicine, tobramycine, nétilmicine, amikacine. (2011). www.afssaps.fr

12 Uusitalo L. Advantages and challenges of Bayesian networks in environmental modelling. Ecol. Modell. 203(3-4), 312-318 (2007).

13 Lazkano E, Sierra B, Astigarraga A, Martínez-Otzeta JM. On the use of Bayesian Networks to develop behaviours for mobile robots. Rob. Auton. Syst. 55(3), 253-265 (2007).

14 López Droguett E, das Chagas Moura M, Magno Jacinto C, Feliciano Silva Jr M. A semi-Markov model with Bayesian belief network based human error probability for availability assessment of downhole optical monitoring systems. Simul. Model. Pract. Theory. 16(10), 1713-1727 (2008).

15 Bourguignon L, Djian C, Duraffourg B, Girouin G, Ducher M. Modélisation du risque de chute par iatrogénèse médicamenteuse chez les sujets âgés. Revue Gériatr. 36(4), 207-213 (2011).

16 Uhart M, Bourguignon L, Maire P, Ducher M. Bayesian networks as decision-making tools to help pharmacists evaluate and optimise hospital drug supply chain. Eur. J. Hosp. Pharm. Sci. Pract. 19(6), 519-524 (2012).

17 Bourguignon L, Goutelle S, Gérard C et al. Amikacin pharmacokinetics in adults: a variability that question the dose calculation based on weight. Thérapie 64(1), 47-53 (2009).

18 Ducher M, Maire P, Cerutti C et al. Renal elimination of amikacin and the aging process. Clin. Pharmacokinet. 40(12), 947-953 (2001). 
19 Jelliffe R, Jelliffe S. Estimation of creatinine clearance from changing serum-creatinine levels. Lancet 298(7726), 710 (1971).

20 Jelliffe R. Estimation of creatinine clearance in patients with unstable renal function, without a urine specimen. Am. J. Nephrol. 22(4), 320-324 (2002).

21 Wurtz R, Itokazu G, Rodvold K. Antimicrobial dosing in obese patients. Clin. Infect. Dis. 25(1), 112-118 (1997).

22 Bayes M, Price M. An essay towards solving a problem in the doctrine of chances. By the Late Rev. Mr. Bayes, F. R. S. Communicated by Mr. Price, in a Letter to John Canton, A. M. F. R. S. Royal Society of London. http://archive.org/ details/philtrans09948070.

23 Battiti R, Tecchiolli G. Training neural nets with the reactive Tabu search. IEEE Trans. Neural Netw. 6(5), 1185-1200 (1995).

24 Sheiner LB, Beal SL. Some suggestions for measuring predictive performance. J. Pharmacokinet. Biopharm. 9(4), 503-512 (1981).

25 Krouwer JS, Monti KL. A simple, graphical method to evaluate laboratory assays. Eur. J. Clin. Chem. Clin. Biochem. 33(8), 525-527 (1995).

26 Pearl J. Causal diagrams for empirical research. Biometrika 82(4), 669-688 (1995).

27 Leray P. Réseaux bayésiens: apprentissage et modélisation de systèmes complexes. (2006). www.researchgate.net/ publication/44019371_Rseaux_baysiens__Apprentissage_ et_diagnostic_de_systemes_complexes

28 Wu X, Li P, Wang N et al. State Space Model with hidden variables for reconstruction of gene regulatory networks. BMC Syst. Biol. 5(Suppl. 3), S3 (2011).

29 Oh JH, Craft J, Al Lozi R et al. A Bayesian network approach for modeling local failure in lung cancer. Phys. Med. Biol. 56(6), 1635-1651 (2011).

30 Zhao D, Weng C. Combining PubMed knowledge and EHR data to develop a weighted bayesian network for pancreatic cancer prediction. J. Biomed. Inform. 44(5), 859-868 (2011).

31 Denaro CP, Ravenscroft PJ. Comparison of Sawchuk-Zaske and Bayesian forecasting for aminoglycosides in seriously ill patients. Br. J. Clin. Pharmacol. 28(1), 37-44 (1989).

32 Cox ZL, Nelsen CL, Waitman LR, McCoy JA, Peterson JF. Effects of clinical decision support on initial dosing and monitoring of tobramycin and amikacin. Am. J. Health Syst. Pharm. 68(7), 624-632 (2011).

33 Chan ALF, Wang H-Y, Leung HWC. Incorporation of a gentamicin dosage calculator into a computerized prescriberorder-entry system. Am. J. Health Syst. Pharm. 63(14), 1344-1345 (2006).

34 Tod M, Lortholary O, Seytre D et al. Population pharmacokinetic study of amikacin administered once or twice daily to febrile, severely neutropenic adults. Antimicrob. Agents Chemother. 42(4), 849-856 (1998).

35 Marik PE. Aminoglycoside volume of distribution and illness severity in critically ill septic patients. Anaesth. Intensive Care. 21(2), 172-173 (1993).

36 Delattre IK, Musuamba FT, Nyberg J et al. Population pharmacokinetic modeling and optimal sampling strategy for Bayesian estimation of amikacin exposure in critically ill septic patients. Ther. Drug Monit. 32(6), 749-756 (2010).

37 Taccone FS, de Backer D, Laterre P-F et al. Pharmacokinetics of a loading dose of amikacin in septic patients undergoing continuous renal replacement therapy. Int. J. Antimicrob. Agents 37(6), 531-535 (2011).

38 Tod MM, Padoin C, Petitjean O. Individualising aminoglycoside dosage regimens after therapeutic drug monitoring: simple or complex pharmacokinetic methods? Clin. Pharmacokinet. 40 (11), 803-814 (2001).

39 Jean-Bart E, Debeurme G, Ducher M, Bourguignon L. Calcul de la première dose d'amikacine: évaluation des recommandations posologiques actuelles. Ann. Pharm. Fr. 71(1), 7-12 (2013). 